\title{
Liver enzymes and lipid profile of malaria patients before and after antimalarial drug treatment at Dembia Primary Hospital and Teda Health Center, Northwest, Ethiopia
}

\section{Fentahun Megabiaw}

University of Gondar College of Medicine and Health Sciences

\section{Tegegne Eshetu}

University of Gondar College of Medicine and Health Sciences

\section{Zeleke Kassahun}

University of Gondar College of Medicine and Health Sciences

MULUGETA AEMERO ( $\nabla$ bmeskel@gmail.com )

University of Gondar College of Medicine and Health Sciences https://orcid.org/0000-0002-0225-9361

\section{Research}

Keywords: Malaria, Anti-malaria drug, Liver enzymes, Lipid profiles, Ethiopia

Posted Date: October 21st, 2021

DOl: https://doi.org/10.21203/rs.3.rs-966828/v1

License: (c) (1) This work is licensed under a Creative Commons Attribution 4.0 International License.

Read Full License

Version of Record: A version of this preprint was published at Research and Reports in Tropical Medicine on March 1st, 2022. See the published version at https://doi.org/10.2147/RRTM.S351268. 
Liver enzymes and lipid profile of malaria patients before and after antimalarial drug treatment at Dembia Primary Hospital and Teda Health Center, Northwest, Ethiopia

Fentahun Megabiaw $^{1}$, Tegegne Eshetu ${ }^{1}$, Zeleke Kassahun ${ }^{2}$, Mulugeta Aemero ${ }^{\text {* }}$

${ }^{1}$ Department of Medical Parasitology, School of Biomedical and Laboratory Sciences, College of Medicine and Health Sciences, University of Gondar

${ }^{2}$ College of Medicine and Health Sciences Specialized and Comprehensive Hospital, University of Gondar

Authors' email address:

Fentahun fentahunmegabiaw@gmail.com; fentahun.megabiaw@uog.edu.et

Mulugeta bmeskel@gmail.com; mulugeta.aemero@uog.edu.et

Tegegne tegegneeshetu5@gmail.com; tegegne.eshetu@uog.edu.et

Zeleke zele6179@gmail.com 


\section{Abstract}

Background: infection with malaria in humans involves liver cell destruction, which alters the levels of liver enzymes and lipid profiles. Although a number of studies have been conducted to address the impact of malaria on liver enzymes and lipid profiles, their findings lack consistency and no studies were conducted after antimalarial drug treatment in the Ethiopian context. This study, therefore, is intended to fill this gap.

Methods: An observational cohort study was conducted at Dembia Primary Hospital and Teda Health Center, from June to August 2020. A total of 88 study participants were recruited using random sampling techniques. Socio-demographic data, capillary and venous blood samples were collected from confirmed Plasmodium-infected individuals. Assessment of liver enzymes and lipid profiles was done using Beckman Coulter DC-700 clinical chemistry analyzer. Data were entered using Epi-data and exported to SPSS version 20 software for analysis. One way ANova, independent t-test, and paired t-test were used to compare the mean liver enzymes and lipid profile. A $p$-value $<0.05$ was considered statistically significant.

RESULTS: Before anti-malaria treatment, among 88 malaria-infected study participants, abnormally elevated AST was observed in $87.5 \%$ of them. Similarly, elevated ALT, ALP, and TG were observed among $12.5 \%, 43.2 \%$, and $17.2 \%$ of the study subjects, respectively. A lower level of HDL was observed among $87.5 \%$ of the study participants, while LDL and TC levels were within the normal range. After anti-malaria treatment,100\% of AST, ALT, HDL, and LDL, and $92 \%$ of ALP, $94.3 \%$ of TC, and $86.4 \%$ of TG results were in the normal range. The mean level of AST (39.70 \pm 3.55 and 55.35 \pm 9.6$)$ and ALT $(22.11 \pm 11.75$, and23.24 \pm 16.05$)$ results were increased, whereas HDL $(28.88 \pm 11.63$ and22.73 \pm 14.26$)$ level decreased from low to higher density parasitaemia. The mean level of AST at posttreatment $(33.90 \pm 15.15)$ was significantly lower compared to the

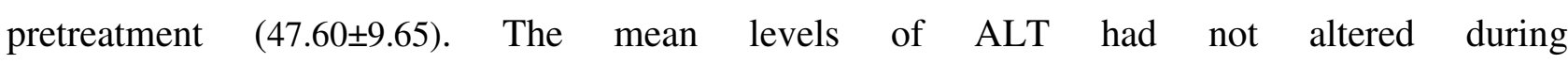
pretreatment(23.53 \pm 16.28$)$ and posttreatment $(23.49 \pm 11.10)$. Moreover, the mean of HDL, LDL, and TC at posttreatment were found to be increased when compared with pretreatment, though it is statistically insignificant $(P>0.05)$.

CONCLUSION: Malaria parasites could be responsible for increased liver enzymes and certain lipids while decreasing some lipid profiles compared with the normal range. After anti-malaria treatment, these parameters were reversed to normal from $86.4 \%$ to $100 \%$. When the mean values are compared, a significant change was observed in AST level while ALT level remains the same. Hence, prompt treatment is important to improve liver enzymes and lipid profile impairment during malaria infection.

Key words: Malaria, Anti-malaria drug, Liver enzymes, Lipid profiles, Ethiopia 


\section{Introduction}

Malaria is a vector-borne infectious disease caused by an intracellular protozoan parasite of the genus Plasmodium that infects multiple hosts, such as Anopheles mosquitoes, humans, and other mammalians(1).Commonly, four predominant Plasmodium species; Plasmodium falciparum, Plasmodium ovale, Plasmodium malariae, and Plasmodium vivax have long been known to cause malaria in human. Nowadays, Plasmodium Knowlesi previously confined to monkeys, is the fifth species that infect humans. However, $P$. falciparum and $P$. vivax are responsible for the majority of malaria cases and $P$. falciparum is mainly renowned in malaria associated deaths. Plasmodium is primarily transmitted by the bite of an infected female Anopheles mosquito, but infection can also occur through exposure to infected blood products and by congenital transmission (2).

Malaria continuous to have a major health problem worldwide (3). It affects $40 \%$ of the world's population which occur more than 100 countries around the globe. More than $70 \%$ of these episodes occurred in sub-Saharan Africa (4). Malaria is also one of the leading public health problems in Ethiopia. The problem covers $75 \%$ of the landmass of the country and $68 \%$ of the populations are living in malaria-risk areas(5). Plasmodium falciparum and $P$. vivax are the two dominant parasite species causing human malaria in Ethiopia, on average, with relative frequencies of about $62.8 \%$ and $37.2 \%$, respectively(6).In Ethiopia, malaria transmission is largely determined by altitude and climate. Most of the malaria transmission occurs between September and December, after the main rainy season June to August(7).

Though malaria parasite can affect many organs, liver is the major organ which is affected (4). The liver is one of the vital organs of the body and it plays a great role in the proper function of the body. It is involved in the uptake, metabolism, phagocytosis and clearance of microorganisms and endotoxins from the portal blood (8). The malaria parasite induces certain metabolic and biochemical changes within the host(9). In the liver stage, sporozoites invade the hepatocytes which can cause organ congestion, sinusoidal blockage, and cellular inflammation. These changes in hepatocytes can lead to the leakage of parenchyma and membrane enzymes into the general circulation(2). 
Liver dysfunction has long been recognized as a clinical feature of malaria(10). Liver failure is the major cause of mortality and morbidity(11). Malaria-induced hepatocyte injury may manifest significant elevated serum level enzymes of aspartate transaminase (AST), alanine transaminase (ALT), and alkaline phosphatase (ALP) (12). The pathogenesis of hepatic dysfunction is not completely known; however, reduction in portal venous flow as a consequence of micro occlusion of portal venous branches by parasitized erythrocytes, intrahepatic cholestasis due to reticuloendothelial blockage and hepatic microvilli dysfunction, suppression of bilirubin excretion due to effect of parasitaemia or endotoxemia or metabolic acidosis, apoptosis and oxidative stress are all mechanisms involved in hepatic damage (13)

Malaria parasites exhibit dyslipidemia due to the parasites use of cholesterol and phospholipids from its host for the increase in surface area and volume of its internal membranes(14). Lipid together with its apoprotein, called lipoprotein, is needed to deliver lipids to and from body tissues to produce energy. Lipoproteins such as chylomicrons, very-low-density lipoproteins (VLDL), low-density lipoproteins (LDL), high-density lipoproteins (HDL), and free fatty acids (FFA) are major lipid components in plasma. Most plasma apolipoproteins, endogenous lipids, and lipoproteins have their origin from the liver. Under normal physiological conditions, the liver ensures homeostasis of lipid and lipoprotein metabolism, thus, hepatocellular damage often associated with severe and acute Plasmodium malaria infections impairs these processes, leading to alterations in plasma lipid and lipoprotein patterns $(9,15,16)$.

Abnormalities in serum lipid profiles play a central role in endothelial functional abnormality which is important in the major risk factors for atherosclerosis including coronary artery disease, cerebrovascular disease, and peripheral vascular diseases $(17,18)$. The extent of serum lipid profile changes during malaria infection and their exact underlying biological mechanisms remain unclear (19). The changes that occur during inflammation and infection are part of the innate immune response and therefore are likely to play an important role in protecting the host. Lipids play a crucial role in the metabolism of Plasmodium in both phases of its life cycle in the human host. These organisms use cholesterol and phospholipids from the host to their metabolic requirements, such as membrane or hemozoin formation. Additionally, the parasite likely modifies metabolic pathways of lipids in the hepatocytes. Moreover, oxidative stress has been associated with the oxidation of lipoproteins, contributing to the abnormalities of lipids level (13, 
20). Hyperlipidemia of malarial infection may result in depletion of natural antioxidants and facilitates the production of reactive oxygen species which can react with all biological molecules like lipids. Thus increased reactive oxygen species and impaired antioxidant defense contributes to the initiation and progression of micro and macro vascular complications in malaria infection(21). Targeting lipid metabolism has been considered attractive for rational antimalarial chemotherapeutic drug design and development (22).

The administration of the right drug against the malaria parasite species to control morbidity and mortality is a very important demand $(23,24)$. Though, the list of anti-malarial drugs is long the most widely known are quinine, chloroquine (CQ), primaquine, and artemisinin and its derivatives. Due to the widespread resistance to monotherapies, the World Health Organization (WHO) recommended the use of Artemisinin-based combination therapies (ACTs) for the treatment of uncomplicated falciparum malaria throughout malaria-endemic areas. ArtemetherLumefantrine (Art-L) having trade names Coartem ${ }^{\circledR}$, is one of the ACTs. Primaquine is known for its activity against the gametocytes of $P$. falciparum and hypnozoites of $P$. vivax or $P$. ovale. $(23,25)$.

Drug-induced liver injury remains largely underestimated(26). Following administration of the selected antimalarial drug, the liver enzymes and lipid profiles have a crucial role in giving information about the disease diagnosis, drug interactions assessment, and prognosis $(22,27)$. In this regard, more recently a number of studies have been conducted to address the impact of malaria on liver enzymes; however, their findings have been unclear due to lack of consistency. Moreover, studies conducted so far were not designed to address the impact of antimalarials on liver enzymes and lipid profiles beyond the impact of malaria itself on liver enzymes and lipid profiles in the Ethiopian context. Considering this gap, this study is aimed to assess liver enzymes and lipid profiles before and after treatment of malaria-infected patients. 


\section{Methods}

\subsection{Study area}

The study was conducted at Dembia primary hospital and Teda health center, which are located within the Amhara regional state, central Gondar, Northwest Ethiopia. Dembia primary hospital is found in Dembia district. It is located $729 \mathrm{~km}$ north of Addis Ababa at $12^{\circ} 18^{\prime} 30^{\prime \prime} \mathrm{N}$ and $37^{\circ} 17^{\prime} 30^{\prime \prime} \mathrm{E}$. The district has an area of $148,968 \mathrm{sq}$. $\mathrm{km}$ and divided into west and east Dembia woreda. The altitude of the district ranges from 1850 to $2000 \mathrm{~m}$ above sea level. The district receives an annual rainfall of 700 to $1160 \mathrm{~mm}$ on average. During the last 15 years, the annual mean maximum temperature was $29.6{ }^{\circ} \mathrm{C}$ and the minimum mean temperature was $13.2^{\circ} \mathrm{C}$ in the District. Teda Health Center is found $24 \mathrm{~km}$ away from Gondar town. Teda town has an average altitude of $1800-2600$ meters above sea level, and the mean rainfall is $771-1160 \mathrm{~mm}$. Malaria is the most prevalent seasonal disease in both areas. From October to December is the peak malaria transmission season in the area. Both $P$. vivax and $P$. falciparum exist in the area with $P$. falciparum prevailing all year (28)

\subsection{Study design and period}

A prospective observational cohort study was conducted from June to August 2020

\subsection{Population}

\subsubsection{Source population}

All clinical malaria suspected participants who are attending Dembia Primary Hospital and Teda health center laboratory during the study period.

\subsubsection{Study population}

All individuals with blood film microscopy positive for malaria and satisfy inclusion criteria that are attending Dembia Primary hospital and Teda health center laboratory during the study period. 


\subsection{Inclusion and exclusion criteria}

\subsubsection{Inclusion criteria}

All malarial patients of both sexes who reside 5-10 $\mathrm{km}$ radius in the study area were included in this study. Moreover, participants with microscopically confirmed for $P$. falciparum and $P$. vivax species or mixed (both falciparum and $P$. vivax) infection were included for this study.

\subsubsection{Exclusion criteria}

Pregnant women, patients with chronic alcoholism, participants having a history of chronic diseases like liver, hepatitis, hypertensive, diabetes mellitus, cardiac disease, renal failure, and other parasitic diseases were excluded in this study. Besides, participants who had been under anti-retroviral therapy, who are positive for $\mathrm{HBsAg}$ and $\mathrm{HCV}$ at the time of screening were also excluded from this study.

\subsection{Sample size determination}

The desired sample size was calculated using the revised 2009 WHO protocol. According to the protocol, the sample size calculation assumes the desired precision of 5\% and a $95 \%$ confidence interval with a minimum of 73 patients. Moreover, considering a potential loss to follow-up, $20 \%$ as a non-response rate was added. Finally, a minimum of 88 participants sample size was determined (29).

$\mathrm{N}=(\mathrm{z} / \mathrm{d}) 2 \mathrm{P}(1-\mathrm{P})$

$=(1.96 / 0.05) 20.05(1-0.05)$

$=73$

Where, $\mathrm{N}=$ number of samples, $\mathrm{P}=$ the expected population proportion of clinical failure $(5 \%)$, $\mathrm{z}=$ confidence interval $(95 \%)$ and $d=$ precision $(5 \%)$

\subsection{Sampling technique}

A random sampling technique was employed to recruit the study participants at Dembia primary hospital and Teda health centers outpatient department (OPD). 


\subsection{Baseline data collection and laboratory methods}

\subsubsection{Questionnaire}

Before study initiation, a standardized questionnaire was developed which was specifically designed to collect socio-demographic characteristics and other previous clinical data of the participant. All relevant personal data were collected using a standard questionnaire after malaria susceptible individuals were confirmed for Plasmodium infections. Socio-demographic (age, gender, and residence, educational and marital status) characteristics and other relevant information were collected via a face-to-face interview technique at Dembia primary hospital and Teda health center OPD by trained data collectors. Following identifying individuals who were parasitologically confirmed for malaria, then the volunteer study participants were linked to laboratory personnel for blood sample collection.

\subsubsection{Blood sample collection and processing}

After getting informed consent and ascent from the study participants, the blood sample was collected following standard operating procedures (SOPs) by trained laboratory personnel in the first visit on day 0 and the follow-up visiting day on day 14. Capillary blood samples from a finger prick was collected aseptically from each study participant to prepare both thick and thin blood film using pre-labeled microscope slides for detection and identification of Plasmodium species. The prepared blood films were stained using 10\% Giemsa solution for 10 minutes and allowed to air dry by putting it horizontally in a slide tray at room temperature. After the stained slides were air-dried both the thick and thin blood film was examined using a high magnification power objective (100X) of the microscope. Thick blood film was used as a screening and quantification of parasitaemia and thin blood film was used primarily for parasite species identification. To determine the density of malaria parasitaemia, two experienced microscopists independently count as Low $(+1 / 1$ to $999 / \mu 1)$, Moderate $(+2 / 1000$ to $9999 / \mu 1)$ and severe or higher $(\geq+3 / 10,000 / \mu \mathrm{l})$ and the asexual stage of Plasmodium parasite on a slide against 200 WBCs in thick blood film from each of the malaria cases. Then, the results of the two readers were averaged and used for the calculation of parasite density. Finally, the result was expressed by parasites per $\mu \mathrm{l}$ blood. It was calculated by using the formula: Parasite $\mu \mathrm{L}=$ Parasite counted/200×Total WBC count $(30,31)$. 
Using an aseptic vein puncture blood sample collection technique, $5 \mathrm{ml}$ of blood sample on day 0 prior to treatment and on days 14 after treatment was collected with a sterile disposable syringe. Then it was delivered into a serum separator test tube for liver enzymes and lipid profile test and kept for (1-2) minutes for clotting. Once the blood samples become clot it was centrifuged at 3000rpm for 5 minutes by using laboratory centrifuge. All participants who were confirmed with Plasmodium infection were tested for hepatitis B surface antigen ( $\mathrm{HBsAg}$ ), hepatitis C (HCV), and intestine parasitic infection to confirm their eligibility. After the study participants were screened for $\mathrm{HBsAg}$ and $\mathrm{HCV}$, serum was separated and stored in plain plastic tubes at $-20^{\circ} \mathrm{c}$ until processed. Each participant was reminded to take their drug at home appropriately and instructed to return back 14 days of post-treatment by giving an appointment card for each participant. Fourteen days of post antimalarial drug administration, all relevant parasitological responses were re-assessed. Moreover, participants who were absent during the follow-up data collection period were considered as loss of follow-up. To assess the impact of malaria on the liver, marker enzymes and lipid profiles were evaluated according to International Federation of Clinical Chemistry (IFCC) methods. These biochemical tests were analyzed on separated serum using standard assay kits by using Beckman Coulter DxC-700 chemistry analyzer. All serum parameters were determined using this chemistry analyzer. The Para-Nitrophenyl phosphate method was used for the determination of serum ALP concentration. Besides, serum ALT concentration was determined by the pyruvate method while AST concentration was measured using the oxaloacetate method. Serum HDL, total cholesterol, LDL, and triglycerides were measured by the enzymatic assay method (32-34). The interpretation of test results was based on the manufacturers manual for each analysis to be measured. The enzymes and lipid profiles were done at the University of Gondar compressive specialized hospital laboratory

\subsubsection{Quality control}

To assure consistency and easy understanding, the questionnaire was prepared in English and translated to the Amharic language. The questionnaire was pre-tested for its accuracy and consistency prior to actual data collection. Socio-demographic and clinical data were collected by trained professionals under the supervision of the investigator. Blood sample quality was insured by collecting and processing according to the SOP. Samples were checked whether they are in the acceptable criteria like: hemolysis, volume, and labeling. The quality control of liver 
enzymes and lipid profile tests was assessed using clinical chemistry laboratory manuals and standard operating procedures (SOPs) of the University of Gondar hospital laboratory.

\subsubsection{Data management and analysis}

Data was checked for completeness and consistency. After cleaning and coding, the data was entered into Epi-data software and exported into SPSS version 20 software for statistical analyses. The Shapiro-Wilks and the Kolmogorov-Smirnov normality test was conducted to check the distributions of the variables, and it showed the data were normally distributed in both pre- and post-assessment with ( $p>0.05)$. Mean, standard deviation, and frequency of quantitative variables were calculated. One way-ANOVA followed by turkey multivariable posthoc test was used to compare the mean liver enzymes and lipid profiles parameters among groups, independent t-test was used to compare the mean of liver enzymes and lipid profiles parameters between males and females, and paired t-test was applied to compare means of case pre and post antimalarial treatment, $p$-value less than 0.05 was considered as statistically significant.

\section{Results}

\subsection{Characteristics of the study participants}

A total of 1,247clinically malaria suspected individuals visiting Dembia primary hospital and Teda health center were screened for malaria during the study period. Of these, $529(42.4 \%)$ had confirmed malaria positive by microscopic method. Among 529malaria-infected patients, 430were excluded since they didn't fulfill the inclusion criteria and 99 were eligible for the study. The major reasons for exclusion were: those who were out of the catchment area, those who had taken drugs for chronic disease, pregnant mothers and those who refused to give consent or assent. Among the 99 who started to participate in study 11 were lost during the follow-up. Thus, the study participants that successfully completed the 14-day follow-up study were 88(fifty-one were from Teda health center and thirty-seven were from Dembia primary hospital).Of this, $64.8 \%$ (57/88) were males and35.2\% (31/88) were females. The mean age of study participants was 26.11 \pm 11.044 years (ranges 6-65years). The predominant age group affected was 25-34 years (31.8\%) followed by 16-24 years (30.7) (Table1). 
Among the 88 study participants, 77(88\%) were infected with P. falciparum, 9(10\%) were infected with $P$. vivax, and 2(2\%) were with mixed infection ( $P$. falciparum and $P$. vivax). In terms of parasitaemia, 42\% (37/88) were diagnosed with high parasitaemia, 27\% (24/88) with moderate parasitaemia, and 31\% (27/88) with low parasitaemia.

Table 1: Socio-demographic characteristics of the study participants at Dembia primary hospital and Teda health center, Northwest Ethiopia, 2020(N=88)

\begin{tabular}{|c|c|c|c|c|}
\hline \multicolumn{2}{|l|}{ Variables } & Male $=57(64.77 \%)$ & Female $=31(35.23 \%)$ & Total $=88$ \\
\hline \multirow[t]{4}{*}{ Age group } & $<15$ & $9(15.8 \%)$ & $3(9.7 \%)$ & $12(13.6 \%)$ \\
\hline & $16-24$ & $16(28.1 \%)$ & $11(35.5 \%)$ & $27(30.7 \%)$ \\
\hline & $25-34$ & $16(28.1 \%)$ & $12(38.7 \%)$ & $28(31.8 \%)$ \\
\hline & $>35$ & $16(28.1 \%)$ & $5(16.1 \%)$ & $21(23.9 \%)$ \\
\hline \multirow[t]{3}{*}{ Marital status } & Single & $39(68.4 \%)$ & $11(35.5 \%)$ & $50(56.8 \%)$ \\
\hline & Married & $18(31.6 \%)$ & $19(61.3 \%)$ & $37(42.0 \%)$ \\
\hline & Widowed & $0(0 \%)$ & $1(3.2 \%)$ & $1(1.2 \%)$ \\
\hline \multirow{5}{*}{$\begin{array}{l}\text { Educational } \\
\text { status }\end{array}$} & Illiterate & $14(24.6 \%)$ & $12(38.7 \%)$ & $26(29.5 \%$ \\
\hline & Primary school & $22(38.6 \%)$ & $7(22.6 \%)$ & $29(33.0 \%)$ \\
\hline & Secondary school & $10(17.5 \%)$ & $7(22.6 \%)$ & $17(19.3 \%)$ \\
\hline & Diploma & $11(19.3 \%)$ & $2(6.5 \%)$ & $13(14.8 \%)$ \\
\hline & Degree and above & $0(0 \%)$ & $3(9.7 \%)$ & $3(3.4 \%)$ \\
\hline \multirow[t]{7}{*}{ Occupation } & Student & $29(50.9 \%)$ & $10(32.3 \%)$ & $39(44.3 \%)$ \\
\hline & Government employee & $10(17.5 \%)$ & $6(19.4 \%)$ & $16(18.2 \%)$ \\
\hline & Daily labor & $2(3.5 \%)$ & $1(3.2 \%)$ & $3(3.4 \%)$ \\
\hline & House wife & $0(0 \%)$ & $13(41.9 \%)$ & $13(14.8 \%)$ \\
\hline & Farmer & $12(21.1 \%)$ & $0(0 \%)$ & $12(13.6 \%)$ \\
\hline & Merchants & $3(5.3 \%)$ & $1(3.2 \%)$ & $4(4.5 \%)$ \\
\hline & Others & $1(1.8 \%)$ & $0(0 \%)$ & $1(1.1 \%)$ \\
\hline \multirow[t]{2}{*}{ Residences } & Urban & $27(47.4 \%)$ & $17(54.8 \%)$ & $44(50 \%)$ \\
\hline & Rural & $30(52.6 \%)$ & $14(45.2 \%)$ & $44(50 \%)$ \\
\hline
\end{tabular}

\subsection{Comparison of liver enzyme and lipid profiles with the normal reference range}

Prior to antimalarial drug administration high abnormality level of AST, ALT, ALP, and TG were observed on $87.5 \%(77 / 88), 12.5 \%(11 / 88), 43.2 \%(38 / 88)$, and $17.2 \%(16 / 88)$ participants, respectively, as compared with normal reference ranges (10-40, 10-55, 32-92, 
and $<150$ ), respectively. Moreover, the serum level of HDL was found below the lower limit of the normal reference range in $87.5 \%$ (77/88) of malaria positive study participants when compared to the normal reference range $(>40)$. In contrast to this, the serum level of LDL and TC among all malaria-infected patients were found within the normal range $(<100$ and $<200)$.

After anti-malaria drug administration, 100\%(88/88) of participants AST, ALT, HDL, LDL and 92\% of participants ALP, $94.3 \%$ participants of TC, and $86.4 \%$ of participants TG were found to be within the normal reference ranges

\subsection{Liver enzymes and lipid profiles before an anti-malaria treatment based on sex}

Based on the independent t-test analysis the study showed that no statistically significant differences in liver enzymes and lipid profile parameters between male and female study participants in pre-treatment (Table 2).

Table 2: Liver enzymes and Lipid changes before anti-malaria treatment based on sex among malaria infected patients $(\mathrm{N}=88)$ at Dembia Primary Hospital and Teda health center, North West Ethiopia, 2020.

\begin{tabular}{|c|c|c|c|c|c|}
\hline Parameters & Sex & Mean \pm SD & $\begin{array}{l}\text { Mean } \\
\text { difference }\end{array}$ & $\begin{array}{l}95 \% \mathrm{CI} \text { of the } \\
\text { difference }\end{array}$ & P-value \\
\hline \multirow{2}{*}{ AST (IU/L) } & Male & $47.77 \pm 9.99$ & \multirow[t]{2}{*}{0.57838} & \multirow[t]{2}{*}{$-3.7-4.88$} & \multirow[t]{2}{*}{0.790} \\
\hline & Female & $47.19 \pm 9.12$ & & & \\
\hline \multirow{2}{*}{ ALT(IU/L) } & Male & $24.82 \pm 19.25$ & \multirow[t]{2}{*}{3.66327} & \multirow[t]{2}{*}{$-2.2-9.5$} & \multirow[t]{2}{*}{0.217} \\
\hline & Female & $21.16 \pm 8.23$ & & & \\
\hline \multirow{2}{*}{ ALP (IU/L) } & Male & $84.75 \pm 55.24$ & \multirow[t]{2}{*}{19.14} & \multirow[t]{2}{*}{$-2.9-41.1$} & \multirow[t]{2}{*}{0.087} \\
\hline & Female & $65.61 \pm 36.74$ & & & \\
\hline \multirow{2}{*}{$\mathrm{LDL}(\mathrm{mg} / \mathrm{dl})$} & Male & $53.23 \pm 28.12$ & \multirow[t]{2}{*}{2.03} & \multirow[t]{2}{*}{$-10.9-14.9$} & \multirow[t]{2}{*}{0.755} \\
\hline & Female & $51.19 \pm 31.02$ & & & \\
\hline \multirow{2}{*}{ HDL (mg/dl) } & Male & $23.12 \pm 10.86$ & \multirow[t]{2}{*}{-1.55} & \multirow[t]{2}{*}{$-8.1-5.0$} & \multirow[t]{2}{*}{0.637} \\
\hline & Female & $24.670 \pm 16.35$ & & & \\
\hline \multirow{2}{*}{$\mathrm{TC}(\mathrm{mg} / \mathrm{dl})$} & Male & $95.40 \pm 34.9$ & \multirow[t]{2}{*}{-8.98} & \multirow[t]{2}{*}{$-26.2-8.3$} & \multirow[t]{2}{*}{0.304} \\
\hline & Female & $104.39 \pm 45.40$ & & & \\
\hline \multirow{2}{*}{$\mathrm{TG}(\mathrm{mg} / \mathrm{dl})$} & Male & $110.65 \pm 468.58$ & \multirow[t]{2}{*}{-11.87} & \multirow[t]{2}{*}{$-37 .-13.7$} & \multirow[t]{2}{*}{0.359} \\
\hline & Female & $122.51 \pm 71.50$ & & & \\
\hline
\end{tabular}

Key: ALT; Alanine Amino Transferase, AST; Aspartate Amino transferase, ALP= Alkaline phosphatase, CI, Confidence interval, IU/L; international unit per litter, mg/dl; milligram per deciliter, $\mathrm{HDL}=$ high-density lipoprotein, $\mathrm{LDL}=$ Low-density lipoprotein, $\mathrm{TC}=$ Total Cholesterol TG =Triglyceride; SD; standard deviation 


\subsection{Liver enzymes and lipid profile parameters change before anti-malaria treatment based on age grouping}

Based on one-way ANOVA analysis of some liver enzymes and lipid profile parameters in different age groups revealed that the serum levels of ALP were found to be decreased when the participant's age groups were increased. These ALP serum measurements were 118.08 \pm 58.5 , $84.85 \pm 52.66,67.21 \pm 48.01,60.71 \pm 28.80$ in the age groups of<15yrs, $16-24 \mathrm{yrs}, 25-34 \mathrm{yrs}$, and $>35 \mathrm{yrs}$, respectively $(P=0.006)$. On the other hand, the alteration of serum level of total cholesterol result was found to be associated in the age groups of <15yrs and 25-34yrs. This association showed an increased level of total cholesterol from the age group <15 (71.2500 \pm $31.11)$ to $25-34 y r s(111.32 \pm 44.07),(P=0.025)$. Other parameters in the association of the participant's age group are indicated (Table 3 ).

Table 3: Some liver enzyme and lipid profile measurements in different age groups of malariainfected participants before treatment $(\mathrm{N}=88)$ at Dembia Primary Hospital and Teda health center, North West Ethiopia, 2020.

\begin{tabular}{|l|l|l|l|l|l|}
\hline \multirow{2}{*}{ Parameters } & \multicolumn{4}{|l|}{ Age of participants and mean \pm SD of parameter's } & \multirow{2}{*}{$P$-value } \\
\cline { 2 - 6 } & \multicolumn{1}{|c}{15} & $16-24$ & $25-34$ & $>35$ & \\
\hline AST (IU/L) & $46.67 \pm 9.42$ & $48.77 \pm 11.46$ & $47.93 \pm 8.53$ & $46.05 \pm 9.06$ & .786 \\
\hline ALT(IU/L) & $18.58 \pm 6.92$ & $26.11 \pm 19.95$ & $27.86 \pm 18.88$ & $17.86 \pm 6.08$ & .074 \\
\hline ALP(IU/L) & $118.08 \pm 58.58^{\times}$ & $84.85 \pm 52.66$ & $67.21 \pm 48.01^{\times}$ & $60.71 \pm 28.80^{\times}$ & $.006^{*}$ \\
\hline HDL(mg/dl & $19.75 \pm 12.47$ & $21.07 \pm 1153$ & $27.29 \pm 1419$ & $24.43 \pm 12.92$ & 0.222 \\
\hline LDL(mg/dl & $37.75 \pm 23.68$ & $47.96 \pm 2427$ & $60.5714 \pm 33.69$ & $56.05 \pm 2818$ & .098 \\
\hline TC(mg/d & $71.2500 \pm 31.11^{\times}$ & $95.67 \pm 3456$ & $111.32 \pm 44.07^{\times}$ & $100.90 \pm 34.42$ & $0.025^{*}$ \\
\hline TG (mg/dl) & $109.92 \pm 70.47$ & $119.15 \pm 5346$ & $117.29 \pm 67.79$ & $108.81 \pm 4098$ & .917 \\
\hline
\end{tabular}

Key: *Statistically significant $(P<0.05)$, ALT; Alanine Amino Transferase, AST; Aspartate Amino transferase, ALP = Alkaline phosphatase, $\mathrm{CI}$, Confidence interval, IU/L; international unit per litter, mg/dl; milligram per deciliter, $\mathrm{HDL}=$ high-density lipoprotein, $\mathrm{LDL}=$ Low-density lipoprotein, $\mathrm{TC}=$ Total Cholesterol TG $=$ Triglyceride; $\mathrm{SD}$; standard deviation 


\subsection{Serum liver enzymes and lipid profiles in different level of parasitaemia among malaria-infected patients before anti-malaria treatments}

During the assessment of some liver enzyme measurements in association with the density of malaria parasitaemia, AST, ALT, and ALP measurements showed an increased serum level in proportion to increasing the density of malaria parasitaemia. In this regard, based on one-way ANOVA analysis, the serum level of AST was found to be significantly increased in malariainfected patients $(P<0.001)$ with the increase in the degree of parasitaemia levels from low, moderate to high $(39.70 \pm 3.55 \mathrm{IU} / \mathrm{L}, 44.42 \pm 3.22 \mathrm{IU} / \mathrm{L}$ and $55.35 \pm 9.69 \mathrm{IU} / \mathrm{L})$, respectively. Moreover, ALT and ALP also were found to be increased proportionally with increasing the density of malaria parasitaemia, but the increases were not statistically significant $(P>0.05 \%)$. On the other hand, serum HDL level was found to be significantly decreased $(P=0.024)$ in a malaria-infected patient when the density of parasitaemia increases from low to moderate parasitaemia. Even though HDL decrease was observed when the parasitaemia level increased from moderate to high, there was no statistically significant association $(P>0.05)$ (Table4).

Table 4: Baseline liver enzymes and lipid profiles in different levels of malaria among malariainfected patients $(\mathrm{N}=88)$ at Dembia Primary Hospital and Teda health center, North West Ethiopia, 2020.

\begin{tabular}{|l|l|l|l|l|}
\hline \multirow{2}{*}{ Parameters } & \multicolumn{2}{|l|}{ Mean \pm SD in different parasitaemia levels with95\% CI } & $P$-value \\
\cline { 2 - 5 } & Low=27(31\%) & Moderate=24(27\%) & High=37(42\%) & \\
\hline AST(IU/L) & $39.70 \pm 3.55(38-41)$ & $44.42 \pm 3.22(43-45)$ & $55.35 \pm 9.6(52-59)$ & $.000^{*}$ \\
\hline ALT (IU/L) & $22.11 \pm 11.75(17-27)$ & $25.58 \pm 20.88(17-34)$ & $23.24 \pm 16.05(18-29)$ & .746 \\
\hline ALP(IU/L) & $73.70 \pm 50.51(54-94)$ & $72.79 \pm 47.03(53-93)$ & $84.54 \pm 52.39(67-102)$ & .586 \\
\hline HDL(mg/dl) & $28.88 \pm 11.63(24 .-33)$ & $19.25 \pm 10.66(15-24)$ & $22.73 \pm 14.26(18-27)$ & $.024^{*}$ \\
\hline LDL(mg/dl) & $60.70 \pm 29.64(49-72)$ & $45.41 \pm 22.71(36-55)$ & $51.13 \pm 31.38(41-62)$ & .160 \\
\hline TC(mg/dl) & $110.22 \pm 40.95(94-126)$ & $90.46 \pm 34.17(76-105)$ & $95.32 \pm 39.29(82-108)$ & .154 \\
\hline TG (mg/dl) & $106.30 \pm 54.23(84-128)$ & $126.25 \pm 47.88(106-145)$ & $113.65 \pm 65.39(92-145)$ & .465 \\
\hline
\end{tabular}

Key: *Statistically significant $(P<0.05)$, ALT; Alanine Amino Transferase, AST; Aspartate Amino transferase, ALP= Alkaline phosphatase, $\mathrm{CI}$, Confidence interval, IU/L; international unit 
per litter, mg/dl; milligram per deciliter, HDL = high-density lipoprotein, LDL = Low-density lipoprotein, $\mathrm{TC}=$ Total Cholesterol $\mathrm{TG}=$ Triglyceride; $\mathrm{SD}$; standard deviation,

\subsection{Alteration of mean liver enzymes and lipid profiles before and after anti-malaria treatment: comparison}

According to the paired t-test analysis, the mean pre-treatment concentration for serum AST was $47.60 \pm 9.65 \mathrm{IU} / \mathrm{L}$ and for post- treatment the concentration was 33.90 $15.15 \mathrm{IU} / \mathrm{L}$. Comparison of pre-treatment and post-treatment mean concentrations showed a t-value of 7.137 with a $p$-value of $<0.001$ ). This post-treatment mean concentration was significantly lower compared to the pre-

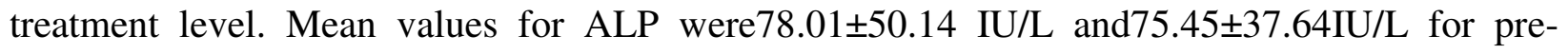
treatment and post-treatment, respectively. Comparison of these two means showed a t-value of 0.550 with a $p$-value of 0.581 , which was not statistically significant. Moreover, there was no ALT alteration during pre-treatment $(23.53 \pm 16.28 \mathrm{IU} / \mathrm{L})$ and post-treatment $(23.49 \pm 11.10 \mathrm{IU} / \mathrm{L})$ in the mean value of ALT level while triglyceride showed insignificant decreases at posttreatment $(104.27 \pm 44.17 \mathrm{IU} / \mathrm{L})$ compared with the pre-treatment $(114.82 \pm 57.57 \mathrm{IU} / \mathrm{L})$ measurements. On the contrary, the mean of HDL, LDL, and total cholesterol at post-treatment were found to be increased compared to pre-treatment $(P>0.05)($ Table5).

Table 5: Alteration of liver enzymes and Lipid profiles measurement before and after ant-malaria treatment among malaria-infected patients $(\mathrm{N}=88)$ at Dembia Primary Hospital and Teda health center, North West Ethiopia, 2020.

\begin{tabular}{|c|c|c|c|c|c|c|c|}
\hline \multirow[t]{2}{*}{ Parameters } & \multirow{2}{*}{$\begin{array}{l}\text { Normal } \\
\text { range }\end{array}$} & \multicolumn{2}{|l|}{ Mean \pm SD } & \multirow{2}{*}{$\begin{array}{l}\text { Mean } \\
\text { difference }\end{array}$} & \multirow{2}{*}{$\begin{array}{l}95 \% \text { CI of } \\
\text { The } \\
\text { difference }\end{array}$} & \multirow{2}{*}{$\begin{array}{l}\text { t- } \\
\text { value }\end{array}$} & \multirow{2}{*}{$\begin{array}{l}p \text { - } \\
\text { value }\end{array}$} \\
\hline & & $\begin{array}{l}\text { Pre- } \\
\text { treatment }\end{array}$ & $\begin{array}{l}\text { Post- } \\
\text { treatment }\end{array}$ & & & & \\
\hline AST(IU/L) & $10-40$ & $47.60 \pm 9.65$ & $33.90 \pm 15.15$ & 13.68 & 9.9-17.5 & 7.137 & $.000 *$ \\
\hline ALT(IU/L) & $10-55$ & $23.53 \pm 16.28$ & $23.49 \pm 11.10$ & .04 & $-3.7-3.8$ & .024 & .981 \\
\hline ALP (IU/L) & $32-92$ & $78.01 \pm 50.14$ & $75.45 \pm 37.64$ & 2.56 & $-6.7-11.8$ & .550 & .581 \\
\hline HDL (mg/dl) & $>40$ & $23.67 \pm 12.99$ & $26.17 \pm 12.28$ & -2.50 & $-5.9-0.9$ & 1.456 & 081 \\
\hline $\mathrm{LDL}(\mathrm{mg} / \mathrm{dl})$ & $<100$ & $52.51 \pm 29.02$ & $60.43 \pm 23.69$ & -7.92 & -15.9 .057 & 1.973 & .052 \\
\hline $\mathrm{TC}(\mathrm{mg} / \mathrm{dl})$ & $<200$ & $98.57 \pm 38.90$ & $102.92 \pm 30.69$ & -4.35 & $-14.7-6.0$ & -.836 & .405 \\
\hline TG (mg/dl) & $<150$ & $114.82 \pm 57.57$ & $104.27 \pm 44.17$ & 10.56 & $-5.0-26.0$ & 1.347 & .182 \\
\hline
\end{tabular}


Key: *Statistically significant $(P<0.05)$, ALT; Alanine Amino Transferase, AST; Aspartate Amino transferase, ALP= Alkaline phosphatase, $\mathrm{CI}$, Confidence interval, IU/L; international unit per litter, mg/dl; milligram per deciliter, HDL = high-density lipoprotein, LDL, Low-density lipoprotein, TC, Total Cholesterol TG, Triglyceride; SD; standard deviation

\subsection{Liver enzymes and lipid profiles after anti-malaria treatment based on types of treatment}

The present study showed that the levels of HDL were significantly high among those study participants treated with Coartem ${ }^{\circledR}$ only compared with those treated with Coartem plus primaquine (39.83 \pm 15.10 and 24.79 \pm 11.46 , respectively) (Table 6). The levels of AST, ALT, ALP, LDL TC, and TG does not show statistically significant difference among study participant treated with Coartem ${ }^{\circledR}$, Coartem ${ }^{\circledR}$ plus primaquine, chloroquine, and chloroquine plus primaquine, based on oneway ANOVA analysis.

Table 6: Comparison of liver enzymes and Lipid changes based on anti-malaria among malariainfected patients at Dembia Primary Hospital and Teda health center, North West Ethiopia, 2020.

\begin{tabular}{|c|c|c|c|c|c|}
\hline \multirow[t]{2}{*}{ Parameters } & \multicolumn{4}{|c|}{ Types of treatment and Mean \pm SD } & \multirow[t]{2}{*}{$P$-value } \\
\hline & Coartem ${ }^{\circledR}$ & Chloroquine & $\begin{array}{l}\text { Coartem }{ }^{\circledR}+\text { Premaqui } \\
\text { ne }\end{array}$ & $\begin{array}{l}\text { Chloroquin } \\
\text { e+Primaqui } \\
\text { ne }\end{array}$ & \\
\hline AST(IU/L) & $27.50 \pm 7.50$ & $33.00 \pm 0.00$ & $34.90 \pm 16.20$ & $29.30 \pm 7.50$ & .573 \\
\hline ALT(IU/L) & $23.33 \pm 10.23$ & $27.50 \pm 12.02$ & $23.77 \pm 11.67$ & $19.57 \pm 3.77$ & .764 \\
\hline ALP(IU/l) & $60.17 \pm 26.75$ & $53.00 \pm 7.10$ & $76.38 \pm 38.58$ & $85.29 \pm 36.87$ & .530 \\
\hline $\mathrm{HDL}(\mathrm{mg} / \mathrm{dl})$ & $39.83 \pm 15.10$ & $34.50 \pm 20.50$ & $24.79 \pm 11.46$ & $26.43 \pm 10.52$ & $.023^{*}$ \\
\hline $\mathrm{LDL}(\mathrm{mg} / \mathrm{dl})$ & $67.67 \pm 7.37$ & $80.00 \pm 12.73$ & $59.14 \pm 25.10$ & $62.14 \pm 17.39$ & .543 \\
\hline $\mathrm{TC}(\mathrm{mg} / \mathrm{dl})$ & $102.00 \pm 46.34$ & $118.50 \pm 7.78$ & $103.85 \pm 28.58$ & $89.57 \pm 41.91$ & .598 \\
\hline TG (mg/dl) & $111.16 \pm 5387$ & $119.00 \pm 69.30$ & $106.48 \pm 43.38$ & $71.14 \pm 32.20$ & .214 \\
\hline
\end{tabular}

Key: *Statistically significant $(P<0.05)$, ALT; Alanine Amino Transferase, AST; Aspartate Amino transferase, ALP= Alkaline phosphatase, $\mathrm{CI}$, Confidence interval, IU/L; international unit per litter, mg/dl; milligram per deciliter, $\mathrm{HDL}=$ high-density lipoprotein, $\mathrm{LDL}=$ Low-density lipoprotein, $\mathrm{TC}=$ Total Cholesterol $\mathrm{TG}=$ Triglyceride; $\mathrm{SD}$; standard deviation 


\section{Discussion}

Assessment of liver function tests and lipid profile parameters plays an important role in effective intervention management in malaria infection. Studies have been undertaken to determine the activities of enzymes like AST, ALT, and ALP among patients with Plasmodium malaria that serve as biomarkers of liver disorders and major lipid components in $\operatorname{serum}(1,22)$

In this study, during the assessment of some liver enzymes and lipid profile parameters prior to anti-malarial drug administration, 87.5\% (77/88) cases of AST, 12.5\%(11/88) of ALT, and 43.2\%(38/88) of ALP were found to be abnormally increased in malaria-infected study participants as compared to normal reference ranges (10-40, 10-55, and 32-92), respectively. A study from India had reported relatively similar ALP (43.33\%), lower AST (75\%), and higher ALT (65\%) levels (35). While $87.5 \%$ of HDL in the current study participants was lower than compared with normal reference ranges (>40), $17.2 \%$ of the study participants' triglyceride result was higher than the normal reference range $(<150)$. Total cholesterol and LDL levels of the study participants were within the normal reference ranges $(<100$ and $<200)$, respectively, before antimalarial treatment was administered. The finding of the present study agreed with a previous study finding conducted in Ethiopia where LDL $(34.7 \pm 23.5)$ and $\mathrm{TC}(88.0 \pm 36.3)$ levels were reported(36) and a similar result from India reported a value of $\operatorname{LDL}(70.45 \pm 22.720)$ and TC(103.52 \pm 35$)$, respectively(33). On the other hand, our study findings are lower than the study conducted in Brazil where TG (55.8\%),HDL (92.8\%), and LDL (97.6\%) levels were reported(37). The possible explanation of the difference in liver enzymes and lipid profiles could be due to the utilization of different cutoff values, malaria species, or the difference of study participants in sociodemographic characteristics such as age and genetic variation.

In the current study, the mean value of ALP with age <15, 16-24, 25-34, and >35yrs range was $118.08 \pm 58.58,84.85 \pm 52.66,67.21 \pm 48.01$, and $60.71 \pm 28.80 \mathrm{mg} / \mathrm{dl}$, respectively. Though a statistically significant decrease was observed in the age group between $<15$ and $25-34$, the serum levels of ALP were found to be decreased when the participant's age groups were increased. This study result is inconsistent with the study conducted in Nigeria where the age group 10-29, 30-

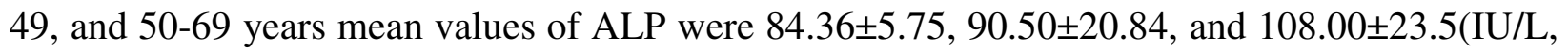
respectively. As the age group increased, enzyme activities also increased $(2,38)$. The genetic 
and nutritional difference might be the possible reason for this variation of ALP activity difference between malaria-infected individuals.

Furthermore, in our finding during the baseline screening, the mean serum level of AST, ALT, and ALP were found to be increased proportionally, but statistical association $(P<0.001)$ was observed only in AST with increasing the degree of parasitaemia levels from low, moderate to

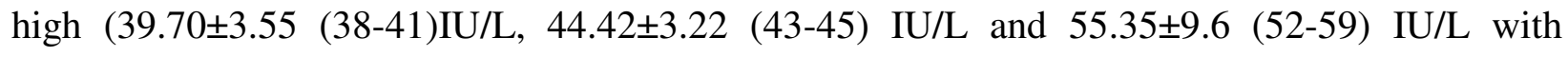
95\%CI, respectively. However, similar AST level finding was reported in Yemen on low parasitaemia level which had $28.36 \pm 1.04$ mean value, but high AST level in moderate $(58.63 \pm$ 3.17IU/L)and high(96.03 $\pm 6.21 \mathrm{IU} / \mathrm{L})$ parasitaemia level $(12)$. On the other hand contrary to the current finding, a study conducted in Nigeria had reported low values of AST (32.30 \pm 16.40 and39.74 $\pm 17.54 \mathrm{IU} / \mathrm{L})$ among low and moderate parasitaemia level patients, respectively(2).This variation could be due to the parasite density and the immunity status, age distribution, and sample size difference of the study participants. Moreover, in our study serum HDL level was found to be significantly decreased $(P=0.024)$ in a malaria-infected patient when the density of parasitaemia increases from low28.88 \pm 11.63 (95\%CI /24-33) $\mathrm{mg} / \mathrm{dl}$ to moderate19.25 \pm 10.66 $(95 \% \mathrm{CI} / 15-24 \mathrm{mg} / \mathrm{dl}) \mathrm{mg} / \mathrm{dl}$ parasitaemia level. Though the HDL level was decreased when the parasitaemia level increased from moderate to high $22.73 \pm 14.26$ (95\% CI/18-27), no significant association was found $(P>0.05)$. No significant association was found on LDL, TC, and TG lipid profiles among the different degrees of parasitaemia. In this study, the finding of HDL is consistent with a previous study done in Ethiopia that HDL mean values were $(22.4 \pm 14.5,19.90 \pm 12.6$ and $18.90 \pm 14.5 \mathrm{mg} / \mathrm{dl})$ in low, moderate, and high parasitaemia levels, respectively(36). The present HDL finding is inconsistent with a study conducted in Nigeria where the HDL mean values were $(46.4 \pm 11.6$ and23.2 $\pm 3.9 \mathrm{mg} / \mathrm{dl})$ in mild and severe malaria, respectively(39). The main reason for this variation might be because of the parasite load, sample size, immunity status, and genetic difference of the malaria-infected study participants.

According to the paired t-test analysis, the mean serum level of AST at post-treatment $(33.90 \pm 15.15 \mathrm{IU} / \mathrm{L})$ was significantly lower when compared to the pre-treatment $(47.60 \pm 9.65 \mathrm{I} / \mathrm{L})$ level which has $13.68 \mathrm{IU} / \mathrm{L}$ mean difference of $t$-value $=7.137(P<0.001)$ and $(95 \% \mathrm{CI} / 9.9$ 17.5IU/L).Moreover, the mean of ALP showed insignificant decreases at posttreatment(75.45 $\pm 37.64 \mathrm{IU} / \mathrm{L})$ compared with the pre-treatment $(78.01 \pm 50.14 \mathrm{IU} / \mathrm{L})(95 \% \mathrm{CI} /-6.7$ - 
11.8IU/L), while there were no ALT alterations between pre-treatment $(23.53 \pm 16.28 \mathrm{IU} / \mathrm{L})$ and post-treatment $(23.49 \pm 11.10 \mathrm{IU} / \mathrm{L})$ with $(95 \% \mathrm{CI} /-3.7-3.8 \mathrm{IU} / \mathrm{L}) .1$ Our AST result is in line with a study done in India where AST mean value of $67.064 \pm 26.027$ and $49.606 \pm 17.966 \mathrm{IU} / \mathrm{L}$ is reported for pre-and post-treatment respectively with $17.46 \mathrm{IU} / \mathrm{L}$ mean difference (40).

Triglyceride level showed insignificant decrease at post-treatment $(104.27 \pm 44.17 \mathrm{mg} / \mathrm{dl})$ compared with the pre-treatment $(114.82 \pm 57.57 \mathrm{mg} / \mathrm{dl})$ at $(95 \% \mathrm{CI} /-5.0-26.0 \mathrm{mg} / \mathrm{dl})$. On the contrary, the mean of HDL(26.82 \pm 12.28 and26.17 $\pm 12.28 I U / L), L D L(52.51 \pm 29.02$ and60.43 \pm 23.69$)$ andTC(98.57 \pm 38.90 and102. $92 \pm 30.69 \mathrm{mg} / \mathrm{dl})$ at post-treatment were found to be decreased in 2.50, 7.92, and 4.35with (95\% CI/ 5.9-0.9,-15.9-.057,-14.7-6.0 mg/dl) when compared with pre-treatment, respectively. However, the increases were not statistically significant $(P>0.05)$. Except for HDL, these study results are in line with a study reported from Nigeria where TG(0.170), TC (0.18), HDL (2.36), and LDL (2.7) $\mathrm{mg} / \mathrm{dl}$ were reported; in Gabon where TC(-12.98), HDL-C (-9.55); LDL(-9.96), and TG levels $(0.9)$ were reported $(22,41) \mathrm{in} \mathrm{mg} / \mathrm{dl}$ of mean difference of pre- and post-treatment, respectively. The mean difference in our findings is inconsistent with the mean difference of other study reports from Nigeria where HDL(1.28), LDL (5.51),TG(4.41), and TC(-6.49)(42), and in India where TC(-12.34),HDL(-1.44), LDL (-3.19) and TG(11.42), respectively(43). The possible explanation for this variation might be due to the physiological, environmental, host immunity, and nutritional status differences.

\subsection{Limitations of the study}

The major limitation of this study is factors that may affect liver enzymes and lipid parameters, such as anthropometric and micronutrient characteristics of patients are not taken into account during the study. The study was only a one round 14 days follow-up. This will have a limitation in the generalization of the findings compared with 28 days follow-up study.

\section{Conclusion and recommendation}

The current study had shown that malaria infection had resulted in the alteration of liver enzymes and lipid profiles. Although TC and LDL levels were within the normal range, there was an increase in AST, ALT, ALP, and TG level while decreased HDL level was observed compared to that of normal reference ranges with the increase in malaria parasitaemia level. After antimalaria treatment, these parameters which deviate from the normal range were reversed. The 
pre-treatment and post-treatment mean values showed significant change in AST level and lower mean serum level on ALP and TG. On the contrary, there was no level difference in ALT between pre-treatment and post-treatment mean values. In general, while malaria infection impairs liver enzyme and lipid function, treatment with antimalarial had reversed its function. However, for solid generalization, we recommend 28 days follow-up study accompanied with anthropometric and nutrition assessment in comparison with apparently healthy individuals.

\section{Abbreviations}

ALT=AlanineAmino-Transferase, $\quad$ ALP=AlkalinePhosphatase, $\quad$ ACTs=Artemisinin-based Combination Therapies, AST=Aspartate Amino-Transferase, BF=Blood Film, CQ=Chloroquine ,HBsAg=Hepatitis B Surface Antigen, HCV=Hepatitis C Virus ,HDL=High Density Lipoprotein ,LFTs=Liver Function Tests, LDL=Low-Density Lipoprotein ,OPD=Outpatient Department, SOPs=Standard Operation Procedures, $\mathrm{TC}=$ Total Cholesterol, VLDL=Very Low-Density Lipoproteins, and WBCs= White Blood Cells

\section{Declaration}

All data is included in the manuscript

\section{Competing interests}

We declare no conflict of interest

\section{Funding}

The research was financially supported by University of Gondar.

\section{Authors' contributions}

The authors contributed equally to this work. FM \& MA had involved in study conception. FM collected and analyzed the data and drafted the manuscript. ZK participated in sample processing. MA and TE supervised the overall work and reviewed the manuscript.

\section{Acknowledgment}

Authors would like to express deepest gratitude for study participants for their interest to participate in the study. Moreover, we would like to acknowledge Dembia primary hospital staff, Teda health center staff, and Gondar comprehensive specialized hospital clinical chemistry staff 
for their positive contribution to the entire work of data collection and processing of this study. Lastly, our deepest gratitude goes to the University of Gondar, College of Medicine and Health Sciences, School of Biomedical and Laboratory Sciences, Department of Medical Parasitology for letting us to do this public health important research work.

\section{Ethics approval and consent to participate}

The study was conducted after ethical approval was obtained from the Research and Ethics Committee of the School of Biomedical and Laboratory Science, College of Medicine and

Health Sciences \& Specialized Hospital, University of Gondar. Moreover, following an explanation of the purpose, the benefits, and the possible risks of the study written informed consent was obtained from adults/guardians and ascents were obtained from all study participants. The participants were free to withdraw from the study at any time. Compensation for transport was provided for every patient's scheduled visit.

\section{Consent for publication}

Not applicable

\section{Availability of data and materials}

All data is included in the manuscript.

\section{References}

1. Latif A, Mansha M, Saif K, Fatima S. HISTOPATHOLOGICAL EFFECTS OF DIFFERENT ARTEMISININ DERIVATIVES ON LIVER OF MALE ALBINO MICE. JAPS, Journal of Animal and Plant Sciences. 2018;28(6):1701-8.

2. Onyesom I, Onyemakonor N. Levels of parasitaemia and changes in some liver enzymes among malarial infected patients in Edo-Delta Region of Nigeria. Curr Res J Biol Sci. 2011;3(2):78-81.

3. Sharma C, Awasthi SK. Recent Advances in Antimalarial Drug Discovery-Challenges and Opportunities. An Overview of Tropical Diseases. 2015:39.

4. Augustine O. Effect of Plasmodium Falciparum on Liver Function Parameters of Children in Akoko Area of Ondo State, Nigeria. Journal of Diagnostics. 2018;5(1):1-5.

5. Taffese HS, Hemming-Schroeder E, Koepfli C, Tesfaye G, Lee M-C, Kazura J, et al. Malaria epidemiology and interventions in Ethiopia from 2001 to 2016. Infectious diseases of poverty. 2018;7(1):1-9.

6. Deress T, Girma M. Plasmodium falciparum and Plasmodium vivax Prevalence in Ethiopia: A systematic review and meta-analysis. Malaria research and treatment. 2019;2019.

7. Alemu A, Abebe G, Tsegaye W, Golassa L. Climatic variables and malaria transmission dynamics in Jimma town, South West Ethiopia. Parasites \& vectors. 2011;4(1):30. 
8. Hoekstra LT, de Graaf W, Nibourg GA, Heger M, Bennink RJ, Stieger B, et al. Physiological and biochemical basis of clinical liver function tests: a review. Annals of surgery. 2013;257(1):27-36.

9. Faucher J-F, Ngou-Milama E, Missinou M, Ngomo R, Kombila M, Kremsner PG. The impact of malaria on common lipid parameters. Parasitology research. 2002;88(12):1040-3.

10. Kochar D, Agarwal P, Kochar S, Jain R, Rawat N, Pokharna R, et al. Hepatocyte dysfunction and hepatic encephalopathy in Plasmodium falciparum malaria. Qjm. 2003;96(7):505-12.

11. Giannini EG, Testa R, Savarino V. Liver enzyme alteration: a guide for clinicians. Cmaj. 2005;172(3):367-79.

12. Al-Salahy M, Shnawa B, Abed G, Mandour A, Al-Ezzi A. Parasitaemia and its relation to hematological parameters and liver function among patients malaria in Abs, Hajjah, Northwest Yemen. Interdisciplinary perspectives on infectious diseases. 2016;2016.

13. Fabbri C, de Cássia Mascarenhas-Netto R, Lalwani P, Melo GC, Magalhães BM, Alexandre MA, et al. Lipid peroxidation and antioxidant enzymes activity in Plasmodium vivax malaria patients evolving with cholestatic jaundice. Malaria journal. 2013;12(1):1-7.

14. Mohanty S, Mishra S, Das B, Satpathy S, Mohanty D, Patnaik J, et al. Altered plasma lipid pattern in falciparum malaria. Annals of Tropical Medicine \& Parasitology. 1992;86(6):601-6.

15. Jiang J, Nilsson-Ehle P, Xu N. Influence of liver cancer on lipid and lipoprotein metabolism. Lipids in health and disease. 2006;5(1):1-7.

16. Sibmooh N, Yamanont P, Krudsood S, Leowattana W, Brittenham G, Looareesuwan S, et al. Increased fluidity and oxidation of malarial lipoproteins: relation with severity and induction of endothelial expression of adhesion molecules. Lipids in health and disease. 2004;3(1):15.

17. Lopes-Virella M, Wohltmann H, Loadholt C, Buse M. Plasma lipids and lipoproteins in young insulin-dependent diabetic patients: relationship with control. Diabetologia. 1981;21(3):216-23.

18. Pfeifer MA, Brunzell JD, Best JD, Judzewitsch RG, Halter JB, Porte D. The response of plasma triglyceride, cholesterol, and lipoprotein lipase to treatment in non-insulin-dependent diabetic subjects without familial hypertriglyceridemia. Diabetes. 1983;32(6):525-31.

19. Visser BJ, Wieten RW, Nagel IM, Grobusch MP. Serum lipids and lipoproteins in malaria-a systematic review and meta-analysis. Malaria journal. 2013;12(1):442.

20. Tran PN, Brown SH, Rug M, Ridgway MC, Mitchell TW, Maier AG. Changes in lipid composition during sexual development of the malaria parasite Plasmodium falciparum. Malaria journal. 2016;15(1):1-13.

21. Khovidhunkit W, Kim M-S, Memon RA, Shigenaga JK, Moser AH, Feingold KR, et al. Effects of infection and inflammation on lipid and lipoprotein metabolism: mechanisms and consequences to the host. The Journal of Lipid Research. 2004;45(7):1169-96.

22. Edikpo N, Okonkwo PO, Adikwu E. Effect of artemether treatment on plasma lipid profile in malaria. Pharmacology \& Pharmacy. 2014;5(07):646.

23. Organization WH. Guidelines for the treatment of malaria: World Health Organization; 2015.

24. Enato EF, Okhamafe AO. Plasmodium falciparum malaria and antimalarial interventions in subSaharan Africa: Challenges and Opportunities. African Journal of Biotechnology. 2005;4(13).

25. Assefa A, Kassa M, Tadese G, Mohamed H, Animut A, Mengesha T. Therapeutic efficacy of artemether/lumefantrine $\left(\right.$ Coartem $^{\circledR}$ ) against Plasmodium falciparum in Kersa, South West Ethiopia. Parasites \& Vectors. 2010;3(1):1-9.

26. Navarro VJ, Senior JR. Drug-related hepatotoxicity. New England Journal of Medicine. 2006;354(7):731-9.

27. Ugokwe $\mathrm{C}$, Asomba $\mathrm{H}$, Onwuzulike I. Hepatotoxicity potential of coartemether on wistar albino rat using liver enzyme assay. Journal of Pharmacy and Biological Sciences. 2015;10:66-70.

28. Addisu A, Tegegne Y, Mihiret Y, Setegn A, Zeleke AJ. A 7-year trend of malaria at primary health facilities in Northwest Ethiopia. Journal of parasitology research. 2020;2020. 
29. Organization WH. Methods for surveillance of antimalarial drug efficacy. 2009.

30. Mathison BA, Pritt BS. Update on malaria diagnostics and test utilization. Journal of clinical microbiology. 2017;55(7):2009-17.

31. Adewoyin A. Peripheral blood film-a review. Annals of Ibadan postgraduate medicine. 2014;12(2):71-9.

32. Oyewole I, Senusie S, Mansaray M. Plasmodium falciparum-induced kidney and liver dysfunction in malaria patients in Freetown, Sierra Leone. Sierra Leone Journal of Biomedical Research. 2010;2(1):70-4.

33. Warjri SB, Ete T, Mishra A, Barman B, Mishra J, Pala S, et al. Association between clinical malaria and Blood Lipids in north eastern India. Journal of Advances in Medicine and Medical Research. 2016:17.

34. Bush V, Smola C, Schmitt P. Evaluation of the Beckman Coulter DxC 700 AU chemistry analyzer. Practical laboratory medicine. 2020;18:e00148.

35. Gurjeet Singh R ADU, Ujwala Maheshwari, Parinita Samant. Role of Liver Enzymes in Patients Infected with Plasmodium vivax

and Plasmodium falciparum. International Journal of Advanced Microbiology and Health Research. 2018;2(1):650-54.

36. Sirak S, Fola AA, Worku L, Biadgo B. Malaria parasitemia and its association with lipid and hematological parameters among malaria-infected patients attending at Metema Hospital, Northwest Ethiopia. Pathology and Laboratory Medicine International. 2016;8:43-50.

37. Dias RM, Vieira JLF, Cabral BdC, da Silva IRP, Brasil LMBF, Araújo EdC, et al. Lipid profile of children with malaria by Plasmodium vivax. Journal of tropical medicine. 2016;2016.

38. Ebenezer D-IO. Evaluation of Some Biochemical Parameters of Plasmodium falciparum Infected Inhabitants of Ekpoma Metropolis, Nigeria. Advances in Biomedical Sciences. 2018;3(1):1.

39. Kiru A, Bala R, Abdulazeez A, Bello S, Adam A, Suleiman S, et al. Lipid Profile and Electrolyte Level in Malaria Patients Attending Muhammadu Abdullahi Wase Specialist Hospital, Kano State, Nigeria. Journal of Complementary and Alternative Medical Research. 2018:1-7.

40. Mannu A, Agarwalla SK, Vasudevan J, Subramaniam K, Ahamed Basha A. Hepatic dysfunction in children with complicated malaria. Int J Contemp Pediatrics. 2018;5:5-28.

41. Visser BJ, de Vries SG, Vingerling R, Gritter M, Kroon D, Kraan RB, et al. Serum lipids and lipoproteins during uncomplicated malaria: a cohort study in Lambarene, Gabon. The American journal of tropical medicine and hygiene. 2017;96(5):1205-14.

42. Jacob EA. Assessment of altered plasma lipid pattern in Plasmodium falciparum malaria infected and non infected individuals. Inter J Hematol Disor. 2014;1(1):27-30.

43. Kullu BK, Majhi C, Pradhan B, Swain DK. Lipid profiles among Plasmodium falciparum infected, non malarial febrile patients and volunteers. International Journal of Advances in Medicine. 2018;5(3):556. 